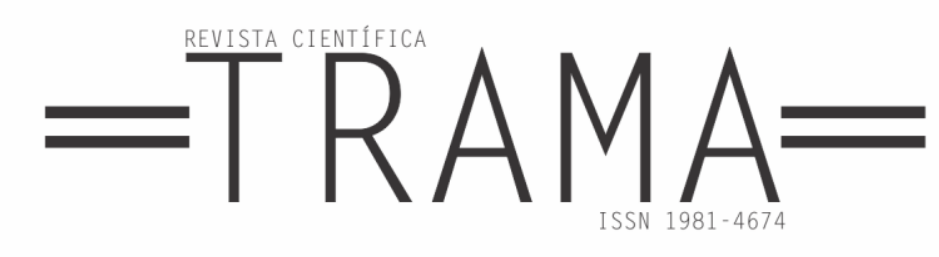

\title{
Do cinema para a literatura: a hibridização MIDIÁTICA ATRAVÉS DO DIÁLOGO ENTRE O FILME DANCER IN THE DARK, DE LARS VON TRIER, E O ROMANCE DAS NACKTE AUGE, DE YOKO YAWADA
}

\author{
Thaís Gonçalves Dias PORTO ${ }^{1}$ \\ Natalia Corrêa Porto Fadel BARCELLOS ${ }^{2}$
}

\begin{abstract}
Resumo: Em Das nackte Auge, Yoko Tawada conta a história de uma jovem vietnamita que, devido a um engano, desembarca na cidade de Paris, onde, impossibilitada de se comunicar com o mundo exterior, encontra no cinema, mais especificadamente nas personagens interpretadas por Catherine Deneuve, um local de refúgio e identificação. As narrativas dos filmes vistos pela personagem contaminam de forma progressiva a narrativa do romance, culminando no último capítulo intitulado Dancer in the Dark, referência ao filme de Lars von Trier, cuja interferência cria uma terceira narrativa. Tal construção intermidiática, típica da literatura contemporânea, é apresentada no romance com o objetivo de suscitar questões acerca da identidade do sujeito do tempo presente e do seu olhar (desnudo) sobre o estranho, o estrangeiro.
\end{abstract}

Palavras-chave: Literatura contemporânea; cinema; identidade; intermidialidade.

\begin{abstract}
Yoko Tawada tells in Das nackte Auge the story of a young vietnamese girl who, due to a mistake, arrives by train in Paris, where she finds herself unable to communicate with this completely foreign world. However, she finds in the movies, more precisely in the characters played by Catherine Deneuve, a place of refuge and identification. The narratives of the movies seen by the character gradually contaminate the novel's narrative, culminating in the last chapter entitled Dancer in the Dark, a reference to Lars von Trier's movie, whose interference creates a third narrative. Such intermedial construction, commonly seen on contemporary works, is presented in this novel in order to place questions around the individual's identity on the contemporary world, as well as it's (naked) look towards the alien, the foreign.
\end{abstract}

Keywords: contemporary literature; cinema; identity; intermidiality.

Recebido em 29-08-2017 Aceito em 05-11-2017

\footnotetext{
${ }^{1}$ Mestranda no programa de Estudos Literários da Universidade Estadual Paulista Júlio de Mesquita Filho - UNESP - Araraquara

${ }^{2}$ Professora Doutora do Departamento de Letras Modernas - Área de Alemão na Universidade Estadual Paulista Júlio de Mesquita Filho - UNESP - Araraquara.
} 


\section{$=$ TRAMA $=$}

\section{Introdução}

A relação estabelecida entre a literatura e o cinema pode ocorrer de diversas maneiras, como: referência, inspiração, complemento ou diferentes leituras acerca de uma mesma temática. Muitos foram os teóricos que procuraram identificar e classificar a maneira como mídias distintas podem ser mutuamente trabalhadas. Dentro da literatura contemporânea é possível notar uma crescente relação entre as letras e a produção fílmica. Um excelente exemplo é o livro da japonesa Yoko Tawada intitulado Das nackte Auge (2004), "O Olho Nu", ainda sem tradução para a língua portuguesa. $\mathrm{O}$ livro conta a história de uma vietnamita que vive como imigrante ilegal na cidade de Paris. Cercada de um mundo completamente estranho e amedrontador, a personagem encontra refúgio nas salas dos cinemas parisienses, mais especificadamente nos filmes em que atuou a atriz francesa Catherine Deneuve, que servem como títulos dos capítulos da obra literária. Com o transcorrer da história, a narrativa de Das nackte Auge mistura-se e confunde-se com as narrativas dos filmes citados, culminando no último e mais significativo deles: Dancer in the Dark (Dançando no Escuro). Trata-se do musical do diretor dinamarquês Lars von Trier em que, assim como no romance de Tawada, uma imigrante encontra na arte seu lugar de refúgio em meio à dura realidade. Assim como há o cinema dentro do romance, o longa de von Trier apresenta os espetáculos musicais como veículo capaz de transportar para uma outra dimensão. O presente trabalho pretende demonstrar como as referências a Dancer in the Dark interferem na narrativa de Das nackte Auge, acentuando os questionamentos acerca da fragmentação da identidade e do sentimento de não pertencimento diante do mundo contemporâneo.

\section{Contemporaneidade na Literatura}

Antes de classificar uma obra como contemporânea, é preciso entender a complexidade que o termo carrega. Karl Erik Schøllhammer (2010, p.9) compreende o contemporâneo como intempestivo, já que a atualidade é representada através de uma inadequação, estranheza, que torna possível o reconhecimento de zonas marginais e obscuras do presente, de modo a "quebrar sua coluna vertebral", não podendo, assim, oferecer repouso ou conciliação, o que torna o passado perdido e o futuro utópico. Há ainda, segundo o autor (SCHØLLHAMMER, 2010, p.107-108), a ficcionalização do material vivo como "um recurso de extração de uma certa verdade", que semeia a "dúvida a respeito da sinceridade enunciativa do eu narrativo", bem como a existência de uma "narrativa errática", cujo 'eu' transita por uma geografia incerta, sem território definido.

Outro teórico que escreve sobre o tema é Suman Gupta (2012, p.36), que entende o contemporâneo como um campo vasto e determinado, uma vez que se têm intensificadas as referências e conexões entre textos literários devido à circulação cada vez mais fluida, ágil e ampla entre idiomas e territórios. O autor (2012, p.141-142) também lembra que o termo identidade, apesar de continuar carregando o conceito convencional de identificação através de documentos oficiais, evoca a questão da identidade por meio do pertencimento a determinados grupos e pela relação entre os grupos, de forma a estabelecer tal questão não somente como um assunto político, mas também social.

Gupta ainda discute (2012, p.85) a potencialização da interferência por parte do próprio leitor na obra literária através, por exemplo, de blogs que escrevem sobre livros ou até mesmo as chamadas fanfictions, em que os fãs de obras 


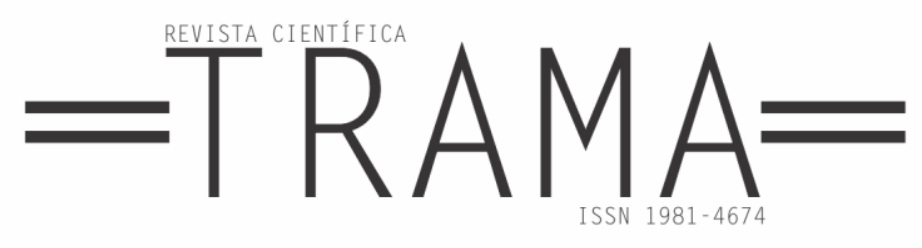

literárias criam novas histórias inspiradas em suas narrativas prediletas. Esse tipo de construção colaborativa possibilita o desdobramento de uma obra em outras plataformas, criando o que se chama de universo expandido. Tal conceito de transmídia foi apresentado por Jenkins (2009, p.138-139) como uma das principais características da cultura de convergência, que, segundo o autor (JENKINS, 2009, p.325), “[...]representa uma mudança de paradigma - um deslocamento de conteúdo de mídia específico em direção a um conteúdo que flui por vários canais[...]". Do mesmo modo, Flávio Carneiro (2005) aponta para o discurso contemporâneo como aquele cuja produção exige a apropriação de elementos midiáticos que propiciam a aproximação entre a chamada "alta" e a "baixa" cultura, ou "cultura de massa".

\section{Literatura Alemã Contemporânea}

Além dos aspectos já mencionados, a literatura alemã contemporânea apresenta diversas particularidades. Wolfgang Emmerich (2006, p. 114) escreveu sobre o "campo amplo" dessa literatura, devido às inúmeras e cada vez mais frequentes novas publicações de novos autores, de modo a ressaltar a importância da delimitação desse território. Emmerich (2006, p.126-128) também lembra da pluralidade de cenas existentes na literatura alemã contemporânea através de quatro diferentes grupos: a geração midiática (com, por exemplo, o livro Autopol do autor de origem búlgara Ilija Trojanow, que se utilizou da internet para compor o romance); novos lugares onde se pode articular o discurso e informar o público (como na televisão a cabo ou nos talkshows); a independência feminina (através de escritoras como Judith Hermann e Jana Hensel); e, por fim, os imigrantes, mais especificamente, a literatura produzida por esses sujeitos (como o turco Aras Ören e a japonesa Yoko Tawada).

Richard Kämmerlings (2011, p.199-200) ressalta a importância do ano de dois mil e dez, quando diversos fatos mobilizaram todo o mundo e promoveram mudanças significativas para o futuro da sociedade, tais como: o lançamento do IPad, que modificou a forma como as pessoas consumiam música e informação; o lançamento do Google Street View, permitindo o acesso de qualquer sujeito a qualquer lugar do mundo dentro de sua própria casa; e, por fim, o escândalo do Wikileaks de Julian Assange. Desta forma, pode-se afirmar que se trata de um ano em que muito se discutiu tanto a respeito da esfera do privado e do público, como também sobre identidade, questões frequentemente abordadas na produção contemporânea. O autor ainda escreve (2011, p.18) sobre a diferença entre a Weltliteratur (literatura mundial), que seria Erfahrungersatz, ou seja, em que o aprendizado ocorre através de experiências que não necessariamente precisam ser vividas pelo leitor; e a Gegenwartsliteratur (literatura contemporânea), que seria $E r$ fahrungsdeutung, isto é, em que a experiência deve ser vivida de modo a evidenciar a importância de sua interpretação.

Diante de todos esses autores, é possível compreender a complexidade em definir e categorizar tal literatura frente à tamanha pluralidade nesse tipo de produção. No entanto, Fadel (2012, p.51) aponta a intermidialidade como um aspecto definidor e influenciador dessa literatura. Irina Rajewsky (RAJEWSKY, 2002 apud PRAßER, 2013, p.112) coloca a intermidialidade como um fenômeno de transposição de fronteiras entre diferentes mídias que, basicamente, divide-se em três grupos principais: a com- 


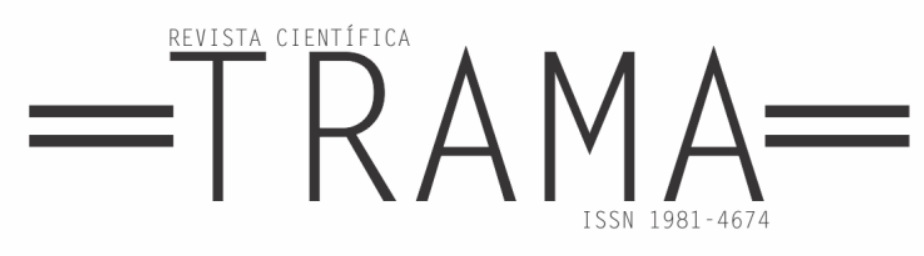

binação de mídias (como os foto-romances de W.G. Sebald, óperas e filmes), a troca de mídia (como a adaptação fílmica de obras literárias) e, por último, as referências intermidiáticas, presente no romance em questão.

\section{Sobre a intermidialidade}

Os processos intermidiáticos de reordenação, reestruturação e reutilização apresentam-se, segundo Oliveira (2012, p.15-16), como uma entrada promissora para a compreensão do presente à medida em que tem-se tal procedimento como um tipo de tradução que retoma a formulação de Kristeva sobre o nascimento da literatura como um "[...]mosaico de textos, de referências e criações anteriores, numa relação intertextual similar a do processo tradutório[...]" (OLIVEIRA, 2012, p.54) que "[...]pode acumular camadas sucessivas de citações, superpondo leituras de releituras de releituras." (OLIVEIRA, 2012, p.64)

É comum a associação entre o conceito de intermidialidade e adaptação. Stam problematiza essa visão apresentando diferentes concepções, tais como:

[...] adaptação enquanto leitura, reescrita, crítica, tradução, transmutação, metamorfose, recriação, transvocalização, ressuscitação, transfiguração, efetivação, transmodalização, significação, performance, dialogização, canibalização, reimaginação, encarnação ou ressurreição (STAM, 2006, p.27).

O autor (2008, p.21) também fala em transtextualidade, nomenclatura proposta por Kristeva, que designa tudo aquilo que coloca o texto, seja de forma explicita ou implícita, em diálogo com outros textos, além de apresentar (2008, p.29) cinco tipos de relações transtextuais que evocam o dialogismo de Genette e a intertextualidade de Kristeva. O primeiro é a intertextualidade, criadora de um "efeito de co-presença de dois textos" na forma de citação, plágio ou alusão, cujo intertexto frequentemente não se mostra explícito, já que se assume o conhecimento prévio das referências. O segundo tipo é a paratextualidade, isto é, a relação entre a obra literária e seus paratextos, que são todas as mensagens acessórias e comentários que circundam o livro e que podem tornar-se "virtualmente indistinguíveis dele." (STAM, 2006, p.29-30) O terceiro tipo de interterxtualidade de Genette é a metatextualidade, "[...] ou a relação crítica entre um tex to e outro, seja quando o tex to comentado é citado explicitamente ou quando é evocado silenciosamente." (STAM, 2006, p.30). O quarto tipo é a arquitextualidade, "[...] ou as taxonomias genéricas sugeridas ou refutadas pelos títulos e subtítulos de um texto." (STAM, 2006, p.32). Por fim, tem-se a hipertextualidade, em que se tem um hipotexto que, sob operações de seleção, ampliação, concretização ou realização, transforma, modifica, elabora ou amplia o hipertexto. (STAM, 2006, p. 33) Nesse sentido, Diniz (2005, p.44) afirma que "quanto maior e mais explícita for a hipertextualização de uma obra, mais sua análise dependerá da decisão interpretativa do leitor."

Segundo Rajewsky (2005, p.4344), os estudos intermidiáticos, desenvolvidos na Alemanha há bastante tempo, apenas mais recentemente ganharam força nos países de língua inglesa, especialmente nos estudos interartes, devido ao crescente interesse na solução de problemas que viabilizem novas possibilidades de se pensar e mostrar a partir de diferentes perspectivas de cruzamento de mídias e hibridizações, graças ao surgimento do que convencionou-se chamar de novas mídias. Apesar dos diversos 


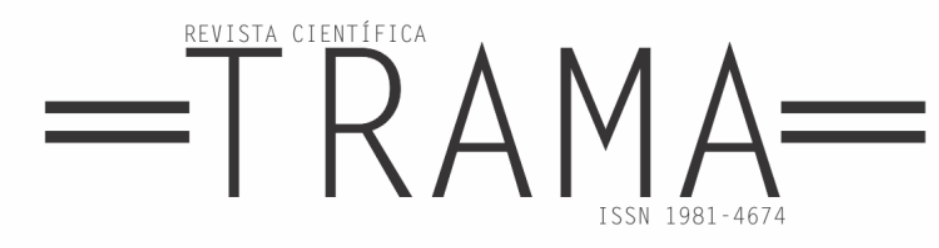

termos, como multimidialidade, plurimidialidade, crosmidialidade, inframidialidade, convergência midiática, integração midiática, fusão midiática, hibridização e etc., a autora (2005, p.44) afirma que as pesquisas buscam especificar o conceito de intermidialidade através de epítetos como transformacional, discursivo, sintético, formal, transmidial, intermidialidade ontológica ou genealógica, intermidialidade primária ou secundária, ou a chamada configuração intermidial. No entanto, isso pode representar perigo, uma vez que tais conceitos podem resultar em imprecisões e equívocos. Diante disso, Rajewsky (2005, p.45) defende uma definição mais especifica do que se entende por intermidialidade, de modo a situá-la em um espectro mais amplo.

Sendo assim, Rajewsky (2005, p.46-47) diferencia três concepções de intermidialidade: A primeira tem a ver com uma abordagem entre sincronismo e diacronismo, em que a intermidialidade é compreendida como uma condição fundamental ou categoria. Já no segundo ponto a intermidialidade é entendida como uma categoria crítica para a análise concreta de configurações ou produtos midiáticos individuais e específicos. A autora (2005, p.48-49) expõe nessa segunda categoria as concepções de diferentes teóricos, que partem do conceito de dialogismo de Bakhtin e a teoria de intertextualidade de Kristeva, como Sybille Krämer, para quem a intermidialidade é uma condição epistemológica de reconhecimento midiático. Já Gaudreault e Marion compreendem que o bom entendimento de um meio implica na sua relação com outras mídias, e, portanto, para eles, a intermidialidade pode ser encontrada em qualquer processo de produto cultural. Para W.J.T. Mitchell todas as mídias são misturas de mídias, o que resulta em uma qualidade intermidial por si só, predominantemente focada na mídia (digital) atual. Tem-se, então, Jay
David Bolter e Richard Grusin, que também chegam à conclusão de que toda mediação é remediação, sendo a remediação um tipo específico de relação intermidial. O terceiro e último ponto opera no nível do fenômeno analisado, de modo que a designação ou não de um fenômeno particular como intermidial depende da disciplina da abordagem proveniente, seus objetivos correspondentes e o conceito (explícito ou implícito) que constitui o meio.

A abordagem de Rajewsky (2005, p. 50-51) leva em consideração uma variedade de alcance mais abrangente dos fenômenos que se distinguem segundo suas distintas qualidades intermidiais na medida em que são propostas subcategorias de intermidialidade, sendo a primeira delas um tipo segundo um senso mais restrito de transposição midiática, que se refere à maneira como o produto midiático surge a partir de uma transformação de um produto existente ou de seu substrato em outro meio. Essa categoria é guiada pela produção, concepção genética de intermidialidade em que o texto original é a fonte de um novo produto midiático, cuja formação é baseada em uma mídia específica e na obrigatoriedade do processo de transformação midial. A segunda categoria entende a intermidialidade sob um aspecto mais limitado de combinação midiática - a dita multimídia, mixmídia e intermídia. Segundo a autora $(2005$, p. 52) essa categoria é determinada pela constituição da constelação midiática de um produto, que é resultado da combinação de, pelo menos, duas mídias diferentes ou da articulação de formas de mídia. Por fim, Rajewsky (2005, p.52-53) apresenta a intermidialidade vista sob a perspectiva das referências intermidiáticas. Por exemplo: referências a um filme em textos literários através de evocação ou imitações de determinadas técnicas fílmicas, tais como zoom, transições ou montagem. Nessa categoria, as referências são 


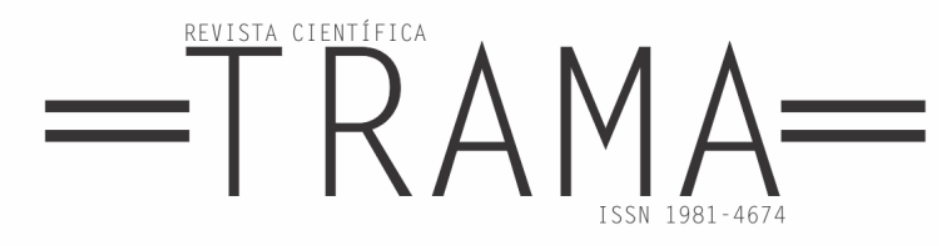

compreendidas como estratégias que constituem significado e que contribuem para o sentido geral do produto midiático.

Algumas dessas operações podem ser claramente identificadas em Das nackte Auge, em especial, no último capítulo do romance, Dancer in the Dark.

\section{Dancer in the dark: características do filme}

O musical Dancer in the Dark, lançado no ano 2000, foi dirigido e roteirizado pelo dinamarquês Lars von Trier, conhecido por seus filmes e declarações polêmicas. O longa conta a história de Selma Jezkova, interpretada pela compositora islandesa Björk. A protagonista do filme é uma imigrante da República Tcheca que vive nos Estados Unidos com seu filho. Durante o filme, é revelado que Selma sofre de uma doença genética que provoca um tipo de cegueira que se intensifica com o passar da idade. Essa foi justamente a motivação que a levou aos Estados Unidos: conseguir juntar dinheiro suficiente para operar seu filho a fim de salvá-lo da escuridão completa. A única personagem que sabe da real condição de Selma é sua amiga de trabalho Kathy, interpretada por Catherine Deneuve.

Apesar da vida pacata, Selma acaba envolvendo-se em uma discussão com o proprietário do trailer onde vive e, por fim, a pedidos dele mesmo, em um impulso de piedade e fúria, ela dispara tiros contra o homem. Na sequência, tentando escapar da realidade, Selma se dirige ao teatro onde ensaia uma montagem de A Noviça Rebelde. Lá ela é recebida pelos colegas que, além de já saberem do assassinato, percebem que a moça parece estar fora de si. Eles simulam um ensaio com o intuito de mantê-la dentro daquele ambiente até que a polícia chegue. O filme termina com a prisão de Selma e sua sentença à morte por enforcamento.

O longa possui um tom melancólico, tanto na sua narrativa quanto na estética. A fotografia conta com muitos tons pasteis, quase acinzentados e pouca luminosidade. Essa falta de cores vibrantes na película condiz com o clima soturno do filme e dialoga com a própria deficiência visual da protagonista.

Os momentos mais alegres acontecem durante os números musicais, como respiros de alívio em meio à trama densa criada por von Trier. Os musicais que Selma tanto ama representam para ela um local de refúgio da realidade. Ela frequenta o cinema para vê-los com a ajuda de Kathy, que conta à amiga tudo o que está sendo projetado na tela.

A precariedade e tristeza da vida da personagem se contrapõem ao mundo de sonhos vividos por ela através dos musicais. Selma não apenas os aprecia, como também devaneia com os mesmos durante todo o filme, transformando sua dura realidade em um alegre número artístico.

Há também no romance de Tawada esse encantamento ilusório causado pela arte, que conduz a personagem principal ao devaneio constante diante da sua dura realidade.

\section{$D_{\text {ancer in the dark } \mathrm{em}}$}

\section{Das Nackte Auge}

Das nackte Auge conta a história de uma jovem vietnamita que é escolhida para palestrar sobre o Vietnã na antiga Berlim Oriental. A jovem, cujo nome nunca é revelado, depara-se com muitos estranhamentos e dificuldades no mundo ocidental. Na noite anterior à sua apresentação, ela participa de uma festa, onde conhece Jörg. O jovem alemão embriaga 


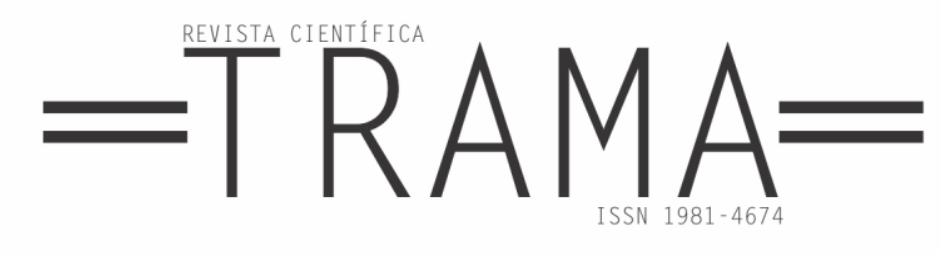

e sequestra a vietnamita. Quando finalmente acorda e retoma a consciência, ela percebe que se encontra na casa de Jörg em Bochum, cidade localizada na antiga Alemanha Ocidental. Ou seja, a vietnamita encontra-se ilegal, já que não possui uma permissão para estar no lado capitalista do país. A jovem vê-se sem alternativa e aceita submeter-se ao alemão sequestrador. Até que um dia fica sabendo da existência de uma linha de trem que liga Paris a Moscou, cuja exata metade do caminho é Bochum. Ela descobre que a linha passa perto da casa e decide fugir para Moscou, onde poderia pedir ajuda para voltar para casa. No entanto, a jovem embarca na direção oposta do trem e acaba indo parar em Paris. Na viagem ela conhece Ai Van, uma vietnamita que vive na capital francesa com seu marido francês, Jean. O casal aceita abrigar a jovem até que ela encontre uma maneira de retornar legalmente para o Vietnã. Contudo, esse objetivo é afetado a partir do momento em que a jovem passa a frequentar os cinemas parisienses e se encantar pela figura da atriz francesa $\mathrm{Ca}-$ therine Deneuve.

Cada capítulo do romance leva o título de um filme em que atuou a conhecida atriz e a relação entre o filme e a narrativa do romance cresce gradativamente com o passar da narrativa. O último e mais significativo capítulo da obra faz referência ao filme de Lars von Trier.

Primeiramente, é possível traçar alguns paralelos entre a personagem vietnamita de Das nackte Auge e Selma, do filme Dancer in the Dark, como: ambas vivem fora de seu país, enfrentam graves problemas sociais e, o mais importante, perdem-se em seus devaneios, sendo a vietnamita por meio dos filmes e a tcheca por meio dos musicais.

\footnotetext{
${ }^{3}$ Tradução nossa: "Selma hatte drei Jahre lang in Berlin gelebt, bevor sie in die USA auswanderte, wo sie später zum Tode verurteilt wurde. Von
}

Diferentemente dos outros capítulos em que a personagem narra a sua própria história majoritariamente em primeira pessoa, este capítulo apresenta-se todo em terceira pessoa, como se a vietnamita estivesse narrando a sua versão da história do filme de Lars von Trier.

O leitor que conhece a trama do longa percebe algumas semelhanças entre seu roteiro e o romance, mas também pode deparar-se com diversos pontos que causem, a princípio, confusão na interpretação da obra ao tentar distinguir o que pertence à narrativa literária e o que pertence ao filme. Na obra de Tawada, Selma esteve em Berlim antes de ir para os Estados Unidos, mas teve o mesmo final trágico da personagem de Björk na película:

Selma morou por três anos em Berlim antes de emigrar para os Estados Unidos, onde ela foi mais tarde sentenciada à morte. Emigrar de Praga para Berlim não foi difícil. Ela se hospedou na casa uma tia proprietária de uma floricultura no bairro de Pankow (TAWADA, 2010, p.183). ${ }^{3}$

Portanto, nota-se nesse trecho uma narrativa em terceira pessoa, cujos detalhes sobre a vida e a origem de Selma funcionariam como um prequel do filme citado. Todavia, não fica exatamente claro se o narrador se refere de fato à personagem do filme de Lars von Trier. Na sequência, o narrador fala sobre uma vizinha de Selma em Berlim, conhecida como a "senhora com o cachorrinho", que, segundo os boatos, havia ficado cega em 1988, depois de se envolver em uma briga na Alexanderplatz para tentar ajudar uma menina que estaria sendo agredida por um grupo de jovens. Desse modo, pode-se afirmar que a

Parg nach Berlin auszuwandern, war nicht schwer gewesen. Sie besuchte eine Tante, die im Stadtteil Pankow ein Blumengeschäft hatte" (TAWADA, 2010, p. 183). 


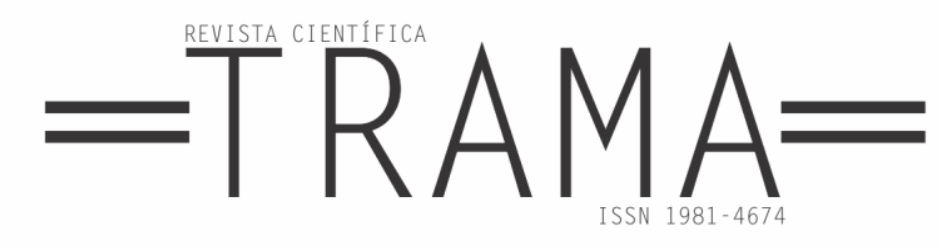

Selma de Yoko Tawada e a Selma de Lars von Trier não são as mesmas personagens, uma vez que, além das origens diferentes (a do filme vem da Tchecoslováquia e a do livro teria morado também em Berlim), as narrativas ocorrem em épocas distintas: uma nos anos sessenta $\mathrm{e}$ outra no final dos anos oitenta.

Na sequência, o narrador conta o dia em que Selma, cujo sonho era trabalhar no teatro, conhece a vizinha que, por sua vez, convida-a para tomar um café. Durante a conversa, Selma revela que nasceu em Praga e a senhora diz que nasceu em Saigon. Depois de saber da origem oriental da vizinha, Selma questiona sua autenticidade, já que sua aparência era, segundo Selma, muito mais europeia do que asiática. A senhora explica, então, que se submetera a uma operação plástica antes de mudar-se para Berlim e que morou dez anos em Paris: "[...] todos os meus antepassados vieram da Ásia. Vivi dez anos em Paris, mas não foi minha culpa.[...] eu achava Paris maravilhosa, mas foi tudo um engano, quiçá um acidente" (TAWADA, 2010, p.183). ${ }^{4}$

A partir desse trecho, pode-se estabelecer a relação entre "a senhora com o cachorrinho" e a personagem do livro de Tawada, pois ambas moraram em $\mathrm{Pa}-$ ris por engano. Com isso, Tawada acentua a indefinição da fronteira entre realidade e ficção. $O$ leitor que conhece $o$ filme pode sentir-se confuso, sem entender qual personagem pertence à obra literária e qual personagem pertence à obra fílmica. Esse recurso é utilizado de forma gradativa por Tawada durante a narrativa. A cada capítulo a quantidade de referências aos filmes e a interferência dos mesmos na história do romance aumenta progressivamente e culmina neste

4 Tradução nossa: "[...]alle meine erfahren stammen aus Asien, übrigens, ich habe zehn Jahre in Paris gelebt, es war nicht meine Schuld.

último, em que a narrativa do filme mistura-se por completo à narrativa literária, parecendo criar uma terceira narrativa, fruto da combinação das duas mídias. $\mathrm{O}$ leitor que desconhece a história do filme tem essa sensação de confusão ampliada, pois surgem subitamente duas novas personagens. O conhecimento dos filmes não é indispensável para o entendimento da obra, no entanto, nesse último capítulo, por fazer referências diretas ao filme, o conhecimento prévio torna-se relevante para a compreensão da obra como um todo.

A personagem de Björk em Dancer in the Dark envolve-se com a ficção ao ponto de transportá-la e transformá-la na sua própria realidade. Para Carrière (2015, p.36), o cinema cria um vínculo quase primitivo ao arrastar-nos "para fora de nós mesmos", o que dificulta a discussão sobre realidade, pois está-se penetrando "num corpo que não é o nosso, num cenário que não é o nosso." Para ele (2015, p.64), o cinema, em sua essência, possui uma necessidade visceral de persuasão quase hipnótica ao apoderar-se de seu espectador a ponto de dominá-lo, manipulá-lo, absorvê-lo e iludilo. A fim de corroborar sua argumentação sobre esse grande poder persuasivo, Carrère utiliza-se das palavras de Buñuel em uma conferência na Universidade do México em 1953:

A pálpebra branca da tela teria apenas que refletir a luz que lhe é peculiar e poderíamos explodir o universo... O filme é uma magnífica e perigosa arma, se manejada por um espírito livre. Ele é o mais admirável instrumento conhecido parar expressar o mundo dos sonhos, da emoção, do instinto. O mecanismo que cria a imagem cinematográfica é, por seu

[...]ich fande Paris wunderbar, aber es war ein Missveständnis, wenn nicht sogar ein Unfall.“ (TAWADA, 2010, p.183). 


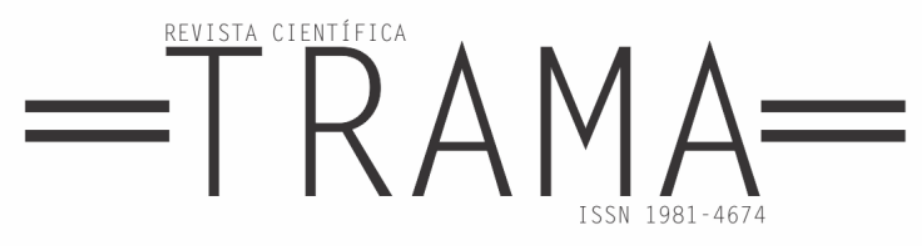

próprio funcionamento, a forma de expressão humana que mais se assemelha ao trabalho da mente durante o sono. Um filme parece ser uma imitação involuntária do sonho... A escuridão que gradualmente invade a sala é o equivalente ao fechar dos olhos. É o momento em que a incursão noturna ao inconsciente começa na tela e nas profundezas do ser humano. Como no sonho, as imagens aparecem e desaparecem em dissoluções, e o tempo e o espaço se tornam flexíveis, contraindo-se ou se expandindo à vontade. A ordem cronológica e a duração relativa não correspondem mais à realidade (CARRÈRE, 2015, p.76).

Com isso, Carrère afirma (2015, p.179-180) que as imagens filmadas sejam, talvez, mais ilusórias que "as máscaras que colocamos sobre o rosto da realidade", pois as "[...] as imagens que sabemos falsas podem nos levar a uma realidade superior, mais forte, mais penetrante e decisivamente mais real do que a própria realidade."

Assim como a protagonista do romance, também Truffaut deixou-se seduzir pela atriz francesa. Segundo o diretor (2005, p. 233) apesar de sua aparência romântica e frágil “[...] Catherine tem [...] o mesmo lado imperturbável e um pudor que, em seu trabalho de atriz, a orientam para nunca se entregar por inteira. Essa contenção faz sonhar, aumenta o mistério [...]" e, com isso, Catherine

[...] acrescenta ambiguidade a qualquer situação, qualquer roteiro, pois dá a impressão de dissimular uma grande quantidade de pensamentos secretos que se deixam adivinhar em segundo plano e, pouco a pouco, tornam-se o essencial e compõe o clima

5 Tradução nossa: "Meine Hand ist meine Leinwand, und die Finger von Kathy sind die Autoren, denn ich bin sicher, dass sie die Geschichte umschreibt, wenn sie ihr nicht gefällt. [...] In einem Film ohne Bilder sind die meisten do filme. Essa impressão de "vida dupla" talvez advenha também de uma espécie de severidade que encontramos em seu olhar. Se o rosto de Catherine é muito doce, o olhar é às vezes bem duro, julgando e exprimindo então grande lucidez (TRUFFAUT, 2005, p. 233).

Portanto, a escolha de Tawada pela musa francesa de sua protagonista em Das nackte Auge não parece ter sido ao acaso.

A semelhança entre a "senhora do cachorrinho" e a jovem vietnamita torna a estreitar-se quando a mulher diz não se incomodar com a cegueira, exceto pelo fato de estar cansada de ouvir música e histórias que os outros insistem em lhe contar, afirmando interessar-se apenas por barulhos. Isso explicaria seu desejo de trabalhar em fábricas (como Selma do filme o faz), onde propaga-se o ruído de máquinas e engrenagens. Logo em seguida, Selma revela que seu grande sonho sempre fora trabalhar no teatro, pois diz-se fascinada pelos palcos. A senhora conta então, como, apesar da cegueira, frequenta o cinema com a ajuda de sua amiga chamada Kathy:

Minha mão é minha tela e os dedos de Kathy são os autores. Não tenho dúvidas de que ela mude a história quando o filme não a agrada. [...] Em um filme sem imagens a maioria dos homens são meros passos. Eles vagam através das noites sem sono, são perseguidos, correm como loucos através de becos ou descem escadas em caracol e se escondem em porões (TAWADA, 2010, p.184).

Tem-se nesse trecho novamente uma aproximação entre as duas obras,

Menschen reine Schritte. Sie wandern durch schlaflose Nächte, werden verfolgt, rasen durch die Gassen oder steigen Wendeltreppen hinunter und vertecken sich im Keller." (TAWADA, 2010, p. 184). 


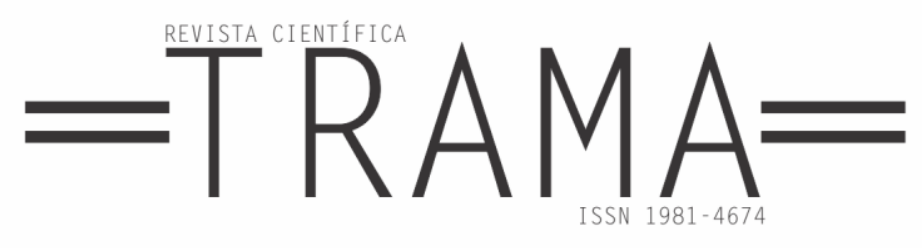

não somente devido aos mesmos nomes das personagens, como também a mesma situação dentro do cinema. Em ambas histórias existe Kathy, que ajuda a amiga cega a "enxergar" o que é do projetado na grande tela.

$\mathrm{Na}$ sequência, a senhora afirma não se importar com a imagem propriamente dita: "Rostos que parecem fotos de passaporte não significam mais nada para mim. Eu queria ver a dança, quer dizer, o estranho e sem sentido movimento das pessoas." (TAWADA, 2010, p.185) ${ }^{6}$. Desse modo, pode-se compreender a identidade pela "foto de passaporte", ou seja, um documento oficial, controlado na entrada e saída dos não-lugares, como os aeroportos. Para a senhora com o cachorrinho esse tipo de identidade não possui valor algum. Hall (2006, p.12) explica que o trânsito promovido pelos encurtamentos das distâncias geográficas favorece a fragmentação do sujeito que, agora, é composto de várias identidades e não é determinado apenas por um documento.

Por fim, Selma pergunta à mulher onde se encontra Kathy e a senhora responde: "Não sei onde ela está agora. Mas quando vou ao cinema ela se senta sempre ao meu lado." (TAWADA, 2010, p. 185$)^{7}$. De acordo com a teoria proposta por Martin (2007, p.22) o filme é capaz de suscitar no espectador um sentimento forte de realidade capaz de levá-lo a crer na existência objetiva do que é projetado na tela. Encontrando-se em um estado completamente suscetível, a protagonista de Das nackte Auge desenvolve exatamente essa percepção colocada por Martin. Ela passa a acreditar cada vez mais nos personagens dos filmes e cada vez menos na realidade incomunicável que a cerca, transformando não somente

6 Tradução nossa: "Die Gesichter, die wie Passbilder aussehen, bedeuten mir nichts mehr. Ich möchte den Tanz sehen, ich meine, die seltsamen, sinnlosen Bewegungen der Menschen“ (TAWADA 2010, p. 185).

a sala do cinema, como a própria imagem projetada em um lugar, que se opõe ao mundo exterior, configurando-o como um não-lugar segundo a definição de Marc Augé. De acordo com Praßer (2013, p.106), quanto mais o filme trabalhar com o interior do personagem, maior será a possibilidade de identificação com o público.

O final do romance proporciona ao leitor essa possibilidade múltipla de leitura, um final aberto que pode ser construído de acordo com o conhecimento das outras narrativas a que o romance faz referência. Com isso, tem-se uma obra literária que dialoga com diferentes obras cinematográficas de diferentes épocas e diretores, de forma a utilizar tais filmes como parte integrante de sua própria narrativa. Ao mesmo tempo, os filmes citados desenvolvem um poder transformador na protagonista, de modo a guiar sua narrativa e gradualmente construir um espaço de identificação, de lugar para a vietnamita junto das personagens da atriz que tanto lhe encanta. $\mathrm{O}$ conhecimento prévio dessas histórias permite ao leitor um tipo de experiência intermidiática que se intensifica no último capítulo de Das nackte Auge, sendo possível até mesmo a criação de uma terceira história, resultante do entrelaçamento da narrativa do livro e do filme de Lars von Trier, como um produto da interferência intermidiática

\section{Conclusão}

O uso de diferentes mídias na composição de uma narrativa não é uma novidade da contemporaneidade. No entanto, torna-se uma característica muito forte da sociedade atual na medida em

7 Tradução nossa: "Ich weiß nicht, wo sie jetzt ist. Aber wenn ich ins Kino gehe, sitzt sie immer neben $\operatorname{mir}[. .$.$] ]“ (TAWADA 2010, p. 185).$ 


\section{$=$ TRAMA $=$}

que cresce o acesso a diversos canais e conteúdos midiáticos. A obra de Tawada trabalha, de modo geral, com o sujeito de um mundo globalizado, onde as distâncias encurtam-se e o interior fragmentase. Ao utiliza-se da ficção dos filmes para enfatizar tais questões que afligem o sujeito contemporâneo, Tawada demonstra a singularidade de sua escrita ao reafirmar o poder desautomatizador da arte.

O filme, enquanto uma obra ficcional, atua dentro da narrativa do livro, que também se caracteriza como ficção. Como produto final, tem-se uma nova narrativa criada a partir do conhecimento prévio do leitor enquanto espectador dos filmes, em especial, do filme de Lars von Trier durante o capítulo Dancer in the Dark. O livro completa o filme e o filme completa o livro. É possível que o leitor passe a imaginar a personagem de Das nackte Auge com as feições da cantora Björk, tamanha experiência transmídia. $\mathrm{O}$ tom sombrio do filme, a ingenuidade e as desventuras de Selma no país estrangeiro dialogam de maneira direta com a história da vietnamita que, devido ao acaso, passa a morar em Paris, mas a viver nas salas de cinema.

O livro convida à reflexão em torno da questão da importância da ficção na vida do sujeito contemporâneo em meio à supermodernidade criadora de não-lugares, procurando desestabelecer a fronteira entre ficção e realidade. Afinal, o que é realidade? Quais são as ficções do cotidiano que o indivíduo se vê obrigado a criar? O cinema, a literatura, as artes em geral, seriam um ponto de fuga da realidade ou uma possibilidade de autoconhecimento? Tawada explora todas essas questões utilizando-se do cinema e de sua relação com a literatura, a fim de propor uma leitura intensa e instigante de sua obra, bem como uma perspectiva frutífera para o estudo de questões interdisciplinares.

\section{$\mathbf{R}_{\text {eferências }}$}

AUGÉ, Marc. Não-lugares - Introdução a uma antropologia da supermodernidade. Campinas: Papirus, 1994.

CARNEIRO, Flávio. No país do presente Ficção brasileira no início do século XXI. Rocco: Rio de Janeiro, 2005.

CARRIÈRE, Jean-Claude. A linguagem secreta do cinema. Rio de Janeiro: Nova Fronteira, 2015.

DINIZ, Thaïs Flores Nogueira. Adaptação como tradução. In: Literatura e cinema: tradução, hipertextualidade, reciclagem. Belo Horizonte: UFMG, 2005, p.19-20.

EMMERICH, Wolfgang. Das literarische Feld Deutschland - 15 Jahre nach der Wende. Universität Bremen: Bremen, 2005. Disponível

em: https://revistas.ucm.es/index.php/RFAL/arti cle/viewFile/RFAL0606110113A/33377.

Acesso em: 30 jan. 2017.

FADEL, Natália Corrêa Porto Sanches. Die Gegenwartsliteratur in der brasilianischen Germanistik. Freie Universität Berlin: Berlim, 2012. Disponível em: http://www.diss.fu-berlin.de/diss/receive/FUDISS thesis 000000036558 .

Acesso em: 30 jan. 2017.

GUPTA, Suman. Contemporary Literature: The Basics. Nova York: Routledge, 2012.

HALL, Stuart. A identidade cultural da pós-modernidade, 10. Ed., Rio de Janeiro: DP\&A, 2006.

JENKINS, Henry. Cultura de convergência. São Paulo: Aleph, 2009.

KÄMMERLINGS, Richard. Das kurze Glück der Gegenwart. Deutschsprachige Literatur seit '89. Stuttgart: Klett-Cotta, 2011.

MARTIN, Marcel. A linguagem cinematográfica. São Paulo: Brasiliense, 2007.

OLIVEIRA, Solange Ribeiro de. Perdida entre signos: Literaturas, artes e mídias, hoje. Belo Horizonte: Faculdade de Letras da UFMG, 2012.

PRAßER, Judith - Der literarische Held und sein mediales alter ego. Freiburg im Breisgau: Albert-Ludwigs-Universität Freiburg im Breisgau, 2013. Disponível em: 
https://freidok.uni-freiburg.de/data/9429.

Acesso em: 30 jan. 2017.

RAJEWSKY, Irina O. Intermediality, Intertextuality, and Remediation: A Literary Perspective on Intermediality. In: History and Theory of the Arts, Literature and Technologies, $n^{\circ} 6,2005$, p. 43-64. Disponível em: http://id.erudit.org/iderudit/1005505ar. Acesso em: 30 jan. 2017.

SCHOLLHAMMER, Karl Erik. Ficção brasileira contemporânea. Rio de Janeiro: Civilização Brasileira, 2010.

STAM, Robert. Teoria e prática da adaptação: da fidelidade à intertextualidade. In: Ilha do Desterro, Florianópolis, $\mathrm{n}^{\circ}$. 51, jul./dez. 2006, p. 19-53. Disponível em: https://periodicos.ufsc.br/index.php/desterro/article/view/2175-8026.2006n51p19. Acesso em: 30 jan. 2017.

A literatura através do cinema: realismo, magia e a arte da adaptação. Belo Horizonte: Editora UFMG, 2008.

TAWADA, Yoko. Das nackte Auge. Tübingen: konkursbuch Verlag Claudia Gehrke, 2010.

TRUFFAUT, François. O prazer dos olhos: textos sobre o cinema / François Truffaut. Rio de Janeiro: Jorge Zahar Ed., 2005.

The Hunger. Direção: Tony Scott, Produção: Richard Shepherd. MGM: Reino Unido, 1983. (96 minutos). 